\title{
Change of Carrying Shaft Innovative Capacity in The Process of Growth of Fatal Cracks
}

\author{
Aleksandr Denisov ${ }^{1 *}$, Artur Asoyan ${ }^{1}$, AlexeyVerkhutov ${ }^{1}$, Natalija $_{\text {Kokodeeva }}{ }^{1}$, and \\ Dmitrij Nikitin ${ }^{1}$ \\ ${ }^{1}$ Yuri Gagarin State Technical University of Saratov, 77 Politekhnicheskaya str., Saratov, 410054, \\ Russia
}

\begin{abstract}
In the paper, the processes of changing the technical state of the crankshaft due to deformation and fatigue failure are considered. The defect method is presented, which allows to estimate the degree of fatigue damage of the crankshaft and to choose the way of restoration of the crankshafts
\end{abstract}

\section{Introduction}

During the engine operation, a regular change in the technical condition of the crankshaft (CV) occurs due to wear, deformation and fatigue failure [1-5]. The first two processes slightly change the bearing capacity of the crankshaft, and fatigue fractures significantly weaken its dangerous sections $[2,3]$. Let's consider this process theoretically and practically.

\section{Theory}

To determine the main factors limiting the resource of the crankshaft, the intensity values of the analyzed processes and the limiting values of the technical state parameters are necessary. In the process of defecting the crankshafts with the opening of critical cracks, the average ratio of the depth $(\mathrm{hm})$ of the crack to its length $(\mathrm{lm})$ was $1: 10$. It is determined that the ratio $\mathrm{hm} / \mathrm{lm}$ depends on the length of the crack, which is reflected in Table 1.

Table 1. Change in the ratio $\mathrm{hm} / \mathrm{lm}$ as a function of crack length.

\begin{tabular}{|c|c|c|c|c|c|}
\hline Intervals $\boldsymbol{l}_{\boldsymbol{m}}, \mathbf{m m}$ & $0-2$ & $2-4$ & $4-6$ & $6-8$ & $8-10$ \\
\hline Ratio $\boldsymbol{h}_{\boldsymbol{m}} / \boldsymbol{l}_{\boldsymbol{m}}$ & $1: 20$ & $1: 10$ & $1: 8$ & $1: 5$ & $1: 3$ \\
\hline
\end{tabular}

The change in this ratio is due to the main stages of the crack propagation, which is schematically shown in Figure 1.

A distinctive feature of fatigue damage (damage) of parts is their lesser suitability for recovery [2-6]. As a rule, parts with fatigue cracks can not be repaired and discarded. One of the most expensive parts of a car subjected to cyclic loads and fatigue damage is the engine

* Correspnding author: denisov0307@yandex.ru 
crankshaft. The degree of fatigue damage of the crankshaft can be estimated from the number (concentration) of fatigue cracks on the necks and fillets.

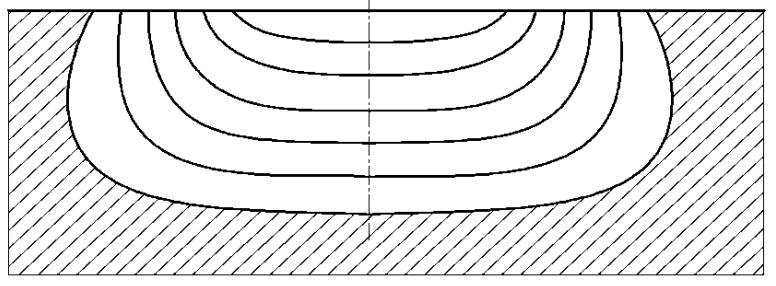

Fig. 1. Stages of fatigue crack propagation.

In operation, the crankshaft is subjected to the action of radial and tangential components of the forces applied to its connecting rods, the centrifugal forces of the rotating masses, the reactions of the supports, as well as the moment of resistance to the rotation of the transmission [2]. The periodic action of these loads causes the appearance of elastic oscillations of the crankshaft (bending and torsional).

Particularly high loads carry crankpins and cheeks of the crankshaft. The nature of the destruction of the elements of the crankshaft indicates the predominant effect of bending moments and a smaller action of the torque (Figure 2). Fatigue fractures (cracks) begin in the area of stress concentrators (fillets, grease holes, dirt traps).

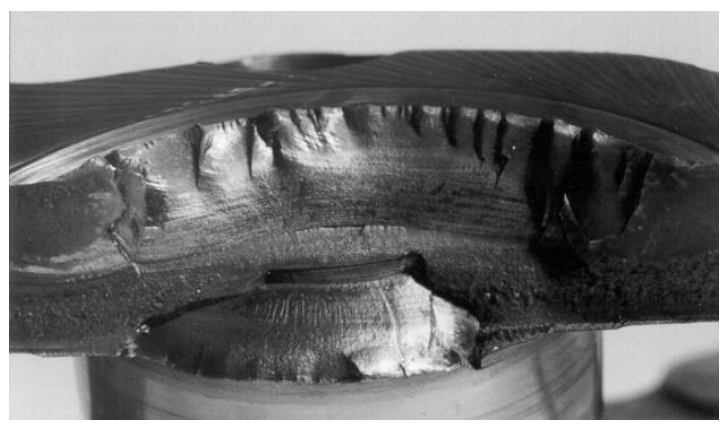

Fig. 2. The form of fatigue failure of the crankshaft on the cheek.

Most often fatigue failure of the shaft occurs along the cheek in the zone of overlapping of the connecting rod necks (Figure 3), which for KamAZ-740 engines is $27.5 \mathrm{~mm}$ at the nominal size of the necks. The bending stresses in the cheek are

$$
\sigma_{u}=\frac{M_{u}}{W}
$$

where $M_{u}$ is the bending moment (practically does not change during operation); $W$ - the moment of resistance of section on a bend.

$$
W=\frac{2 J}{S_{n}},
$$

Where $J$ is the moment of inertia of the cross section of the overlap (Figure 3)

$$
J=\frac{S_{c h} \cdot S_{n}^{3}}{12}
$$


Where $S_{c h}$ is the width of the cheek; $S_{n}$ is the minimum distance between the fillets of the necks (Figure 3).

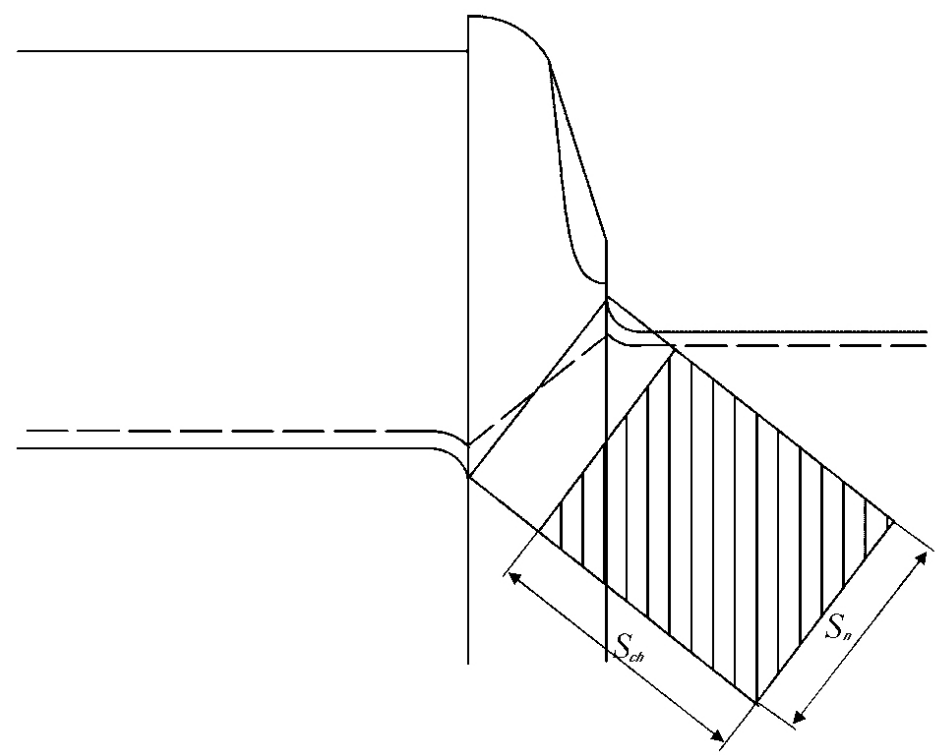

Fig. 3. Diagram of the dangerous section of the cheek and its variation when polishing the necks.

When polishing the crankshaft and crankpieces under the last repair size, the overlap is reduced by $2 \mathrm{~mm}(7.2 \%)$. Calculations according to formulas $(1-3)$ show that the level of bending stress is increased by an average of $8 \%$. The carrying section is substantially reduced during operation due to the propagation of fatigue cracks [7-11] from the foci (in this case fillets) [2-5], as shown in Fig.1 and 2.

The fracture focus is located in the fillet zone. A longitudinal-radial crack is formed when bulk hardening. The crack propagation depth is in the range of $15 \div 20 \mathrm{~mm}$. This amounts to $55-75 \%$ of the area of the dangerous section, taking into account the shape of the crack (Figures 1, 4).

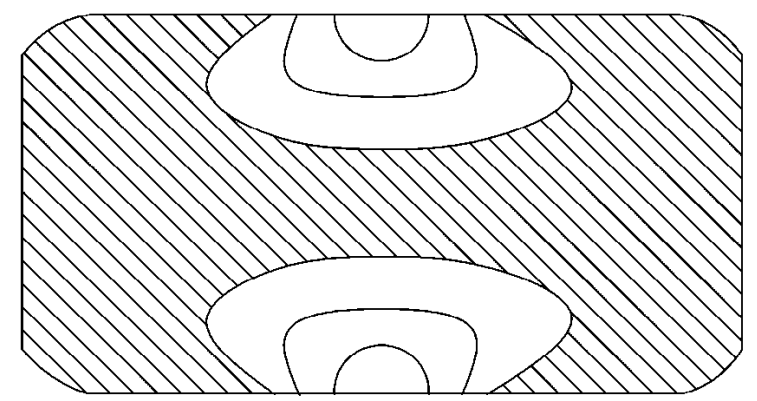

Fig. 4. Diagram of the development of fatigue cracks in the dangerous section of the cheek from foci on fillets.

The most common methods of defecting crankshafts for fatigue cracks are the vibroacoustic method.

The essence of it is that when you strike a suspended crankshaft, sound vibrations of a certain tone occur. As the fatigue cracks accumulate during operation, the height of this tone changes [12-15]. 
For practical use of this principle, it is objectively necessary to use a sound recording device and a signal decoder based on a computer, as well as the connection of sound parameters with the degree of fatigue failure determined using other methods. Currently in the SGTU Gagarin Yu.A. Such equipment is created and statistical data is collected to determine the standards of defects.

The choice of the way to repair the crankshaft is due to the technical condition (the combination of defects) when repairing the engine [2]. The following options and recommended recovery methods are possible. When carrying out preventive repairs of the KAMAZ-740 engine when the car runs under the conditions of the third category of operating conditions of 120-150 thousand $\mathrm{km}$, the parameters of wear and ovality of the necks do not require their polishing, and only polishing is sufficient. At the same time, according to the results of the defect, it is possible to correct the crankshaft, preferably with the use of embossing.

When carrying out the overhaul of the KAMAZ-740 engine with the operating time of 200-250 thousand $\mathrm{km}$, the following options are possible. According to the parameters of wear and ovality of the necks, it is required to grind them to the next repair size and correct the crankshaft. In the presence of scuffing, there are options: polishing the necks through one or more repair dimensions, and also the use of restoring the crankshaft necks with the use of overlaying metal covers is not ruled out. In the presence of cracks, their depth is analyzed from the measured length and the transfer table. If the depth of the fracture is less than half the repair interval (on the side), the grinding is carried out to the next size, if more - then one or more repair sizes in accordance with the depth of the crack.

If the depth of the fracture is more than half the last repair interval, then restoration is possible only using surfacing or a similar method (sputtering, metallization, welding of plates, etc.). It should be noted that the depth of the melted layer is on average $2 \mathrm{~mm}$ with a diameter of the welded wire of $1.6-1.8 \mathrm{~mm}$. If the depth of the fracture is greater than the depth of penetration, then part of it remains under the deposited layer and will continue to increase in the future and may lead to the crankshaft breakage.

Based on the theoretical and experimental studies carried out, the technological process for the restoration of the crankshafts of KAMAZ-740 engines has been improved. The main improvement was carried out in the case of defects in FV for fatigue cracks.

Troubleshooting crankshaftis performed in the circuit shown in Fig. 5. The first block includes Troubleshooting for wear, ovality of necks and deflection of the shaft $\left(S_{l}\right)$. Under this conditions the repair was performed $\left(P_{l}\right)$, including pereshlifovyvayut necks under the next repair size, editing by chasing and polishing necks.

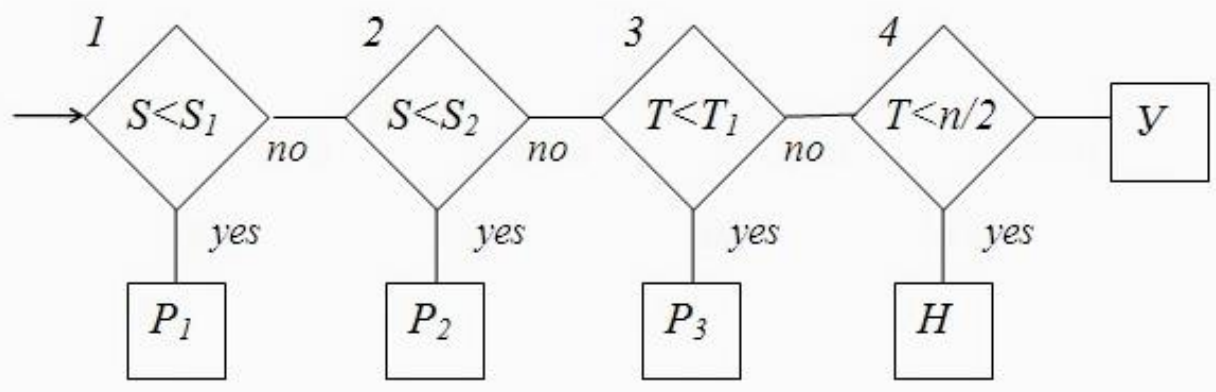

Fig. 5. The scheme of algorithm of defect of a cranked shaft.

The second unit includes a wear defect as a result of neck seizure $\left(S_{2}\right)$ and deflection of the shaft. If this condition is met, repairs are carried out $\left(P_{2}\right)$, including polishing the necks through a regular repair size, straightening by embossing and polishing the necks. The third block includes a defect in the depth of the neck crack $\left(T_{I}\right)$ and deflection of the shaft. If this 
condition is met, repair $\left(P_{3}\right)$ is carried out, including polishing the necks through several repair sizes, straightening by embossing and polishing the necks.

The fourth block includes a defect in the depth of the crack of the necks $(T)$ and the deflection of the shaft. If the depth of the crack is not exceeded, half of the repair allowance, a restoration is carried out using overlaying metal coverings $(H)$ with subsequent machining. If this condition is not observed, the shaft is sent to the scrap.

Economic calculations of the cost of recovering the crankshaft of the KAMAZ-740 engine using advanced technology with an annual program of $300 \mathrm{~kW}$ are given in the appendix. It can be seen that the cost of rebuilding $\mathrm{KV}$ is 6777 rubles. If you take the level of profitability of $25 \%$, then the service price is 8500 rubles, which is $8.5 \%$ of the cost of the new crankshaft. This ensures a secondary shaft resource of at least $80 \%$.

The relative decrease in unit costs due to the reduction in culling for fatigue cracks is $21 \%$. This value should be taken into account in the economic evaluation of the effectiveness of research results.

Thus, the introduction and use of the improved structure of the maintenance and repair cycle of crankshaft and technology of its restoration allows to increase its maintainability and extend the life of engines.

\section{Conclusions}

Taking into account the obtained ratios of the length and depth of the fatigue crack, the dependence of the average depth of fatigue cracks on the crankshaft running time and the confidence area with a confidence probability of 0.8 are established. This dependence is used in the development of the algorithm for defecting the crankshaft.

The specific costs associated with the total culling of crankshaft by the end of its life are 0.106 rubles / km, of which the non-repairable shafts of the fourth repair size can be restored to $21 \%$, the reduction in unit costs for them will be 0.025 rubles per km.

The technological process of restoration of the crankshafts of KAMAZ-740 engines has been improved. The main improvement was carried out in the case of defects in FV for fatigue cracks according to the developed scheme of the defect algorithm. The cost of recovering the crankshaft using the improved process technology is $8.5 \%$ of the cost of the new crankshaft, but it provides a secondary shaft resource of at least $80 \%$.

Due to lower costs for ensuring the efficiency of engines due to the reduction in the elimination of crankshaft for fatigue cracks and loss of car revenue due to reduced downtime in repair, the annual economic effect is 11500 rubles.

\section{References}

1. V. Kanarchuk, A. Chigrinets, L. Golyak, P. Shotsky, Restoration of automotive parts: technology and equipment. M., Transport, 303 p. (1995)

2. A. Denisov, Bases of working capacity of technical systems: the textbook / A.S. Denisov. - Saratov: Sarat. state. tech. Univ., 312 p. (2014)

3. Y. Shi, L. Dong, H. Wang, G. Li, S. Liu. Fatigue features study on the crankshaft material of 42CrMo steel using acoustic emission. Frontiers of Mechanical Engineering; 11(3), p. 233-241. (2016)

4. W. Li, Q. Yan, J. Xue, Analysis of a crankshaft fatigue failure. Engineering Failure Analysis; p. 139-147. (2015)

5. M. Fonte, B. Li, L. Reis, M. Freitas, Crankshaft failure analysis of a motor vehicle. Engineering Failure Analysis; p. 147-152. (2013) 
6. K. Aliakbari, Failure analysis of four-cylinder diesel engine crankshaft. Journal of the Brazilian Society of Mechanical Sciences and Engineering. 41(1), 30. (2018)

7. W. He, X. Xiao, B. Chen, Z. Yang, Z. Zhang, Based on the stress intensity factor calculation of EQ4H type internl combustion engine crankshaft with crack. Jixie Qiangdu/Journal of Mechanical Strength. 38(2), p. 369-373. (2016)

8. N.-N. Sun, G.-X. Li, S.-Z. Bai, Y. Wang, T. Wei, Analysis of crankshaft fatigue based on stain-life theory. Neiranji Gongcheng/Chinese Internal Combustion Engine Engineering. 35(6), p. 60-64 and 83. (2014)

9. G. Cai, Y. Huang, Y. Li, Crankshaft vibratory stress relief process analysis and device design. Zhendong Ceshi Yu Zhenduan/Journal of Vibration, Measurement and Diagnosis. 33(SUPPL.1), p. 97-101. (2013)

10. X. Zhou, X. Yu, Fatigue crack growth regular tests for engine crankshaft and analysis on the mechanism. Jixie Gongcheng Xuebao/Chinese Journal of Mechanical Engineering. 44(1), p. 238-242. (2008)

11. K. Vansovich, Model of growth of fatigue surface cracks for the cycle "loadunloading". Omsk scientific bulletin. No. 3 (153). p. 49-53. (2017)

12. V. Goltsev, V. Markochev, A technique for studying the growth processes of fatigue cracks at a constant sweep of the stress intensity factor. Deformation and destruction of materials. № 7. p. 43-47. (2012)

13. E. Mamaeva, Yu. G. Matvienko, O. Priymak, S. Chuvaev Calculated dependencies for estimating the growth rate of fatigue cracks in low-alloy steels. Factory laboratory. Diagnostics of materials. T. 74. № 2. p. 38-46. (2008)

14. M. Georgiev, N. Mezhova, Distribution of short fatigue cracks. Factory laboratory. Diagnostics of materials. T. 72. № 3. p. 55-58. (2006)

15. Kh. Saidov, F. Saidov, Experimental study of the propagation of a fatigue surface crack. Actual scientific research in the modern world. No. 7-1 (27). p. 99-103. (2017) 